Research Article

\title{
Dual Solutions on Thermosolutal Marangoni Forced Convection Boundary Layer with Suction and Injection
}

\author{
R. A. Hamid, ${ }^{1}$ N. M. Arifin, ${ }^{1}{ }^{\text {R. Nazar, }}{ }^{2}$ F. M. Ali, ${ }^{1}$ and I. Pop ${ }^{3}$ \\ ${ }^{1}$ Institute for Mathematical Research and Department of Mathematics, Universiti Putra Malaysia, \\ UPM Serdang, Selangor 43400, Malaysia \\ ${ }^{2}$ School of Mathematical Sciences, Faculty of Science E Technology, Universiti Kebangsaan Malaysia, \\ UKM Bangi, Selangor 43600, Malaysia \\ ${ }^{3}$ Faculty of Mathematics, University of Cluj, CP 2533400 Cluj, Romania \\ Correspondence should be addressed to N. M. Arifin, norihan@math.upm.edu.my
}

Received 30 September 2010; Accepted 15 January 2011

Academic Editor: Saad A. Ragab

Copyright (C 2011 R. A. Hamid et al. This is an open access article distributed under the Creative Commons Attribution License, which permits unrestricted use, distribution, and reproduction in any medium, provided the original work is properly cited.

This paper considers the extended problem of the thermosolutal Marangoni forced convection boundary layer by Pop et al. (2001) when the wall is permeable, namely, there is a suction or injection effect. The governing system of partial differential equations is transformed into a system of ordinary differential equations, and the transformed equations are solved numerically using the shooting method. The effects of suction or injection parameter $f_{0}$ on the velocity, temperature, and concentration profiles are illustrated and presented in tables and figures. It is shown that dual solutions exist for the similarity parameter $\beta$ less than 0.5 .

\section{Introduction}

Thermosolutal Marangoni forced convection boundary layer flow refers to the thermal and solutal concentration in Marangoni forced convection boundary layer flow due to the surface tension gradients. The study of Marangoni convection has attracted the interest of many researchers in recent years. This is mainly because of its vast contributions in the industrial field especially in the art work of dyeing on the ground (Kuroda [1]) and in the field of crystal growth (Arafune and Hirata [2]). Some of the relevant works are done by Christopher and Wang [3] who studied the effects of Prandtl number on the Marangoni convection over a flat plate. They have also presented a similarity solution for Marangoni flow for both the momentum and the energy equations assuming a developing boundary 
layer along a surface. Besides, Chamkha et al. [4] have dealt with a steady coupled dissipative layer, called Marangoni mixed convection boundary layer. The mixed convection boundary layer is generated when besides the Marangoni effects there are also buoyancy effects due to the gravitational and external pressure gradient effects. Furthermore, in the following papers, numerical solutions on Marangoni boundary layers in various geometries were discovered, analyzed, and discussed, for instance, papers by Golia and Viviani [5], Dressler and Sivakumaran [6], Al-Mudhaf and Chamkha [7], and Magyari and Chamkha [8]. An excellent paper on Marangoni boundary layer flow along the interface of the immiscible nanofluid by Arifin et al. [9] has been recently published. They show that the results indicate that dual solutions exist when $\beta<0.5$. The paper complements also the work by Golia and Viviani [5] concerning the dual solutions in the case of adverse pressure gradient.

Investigations into the effects of suction and injection on the boundary layer flow have generated the interest of many researchers nowadays. Pop and Watanabe [10] analyzed the effects of uniform suction or injection on the boundary layer flow and heat transfer on a continuous moving permeable surface. Meanwhile, Hamza [11] obtained the similarity solution for a flow between two parallel plates (rectangular or circular) approaching or receding from each other with suction or injection at the porous plate. Shojaefard et al. [12] investigated the numerical study concerning flow control by suction and injection on a subsonic airfoil. They discovered that the surface suction can significantly increase the lift coefficient; meanwhile, the injection decreases the skin friction.

The existence of dual solutions or second solutions has aroused a lot of interest of many authors. We mention here some of the papers that discovered the dual solution in their problems. For example, papers by de Hoog et al. [13], Ingham [14], Ramachandran et al. [15], Xu and Liao [16] and Ishak et al. [17-19]. Ridha [20] considered the dual solutions of two coupled third-degree nonlinear ordinary differential equations associated with the incompressible viscous laminar flow along a corner. Further, $\mathrm{Xu}$ and Liao [16], obtained the dual solutions of boundary layer flow over an upstream moving plate using the homotopy analysis method (HAM). Ishak et al. [19] discovered the dual solution of the classical Blasius problem. In their study, they considered the boundary layer flow over a static flat plate and introduced a new parameter, namely, the velocity ratio parameter to analyze the case when both the flat plate and the free stream are in moving situations. Dual solutions are found to exist when the plate and the free stream move in the opposite directions.

In this paper, we extend the problem by Pop et al. [21] by taking the effects of suction or injection for the boundary layer flow. We would also like to investigate whether the dual solutions exist in the above problem. To validate our findings, we have compared the present results with those of Pop et al. [21] for the case of impermeable surface. It is found that the results are in very good agreement. The effects of suction and injection parameter on the surface velocity, temperature, and concentration as well as on velocity, temperature, and concentration profiles are discussed and illustrated in tables and figures.

\section{Mathematical Formulation}

We consider the steady two-dimensional flow along the interface $S$ of two Newtonian immiscible fluids, where $x$ and $y$ are the axes of a Cartesian coordinate system. We also assume that the temperature and concentration at the interface are $T_{S}(x)$ and $C_{S}(x)$, respectively. Besides, the surface is assumed to be permeable so as to allow for possible suction or injection at the wall (Al-Mudhaf and Chamkha [7]). Under the usual boundary- 
layer approximations, the basic governing equations are (see Pop et al. [21])

$$
\begin{gathered}
\frac{\partial u}{\partial x}+\frac{\partial v}{\partial y}=0 \\
u \frac{\partial u}{\partial x}+v \frac{\partial u}{\partial y}=u_{e} \frac{d u_{e}}{d x}+v \frac{\partial^{2} u}{\partial y^{2}} \\
u \frac{\partial T}{\partial x}+v \frac{\partial T}{\partial y}=\alpha \frac{\partial^{2} T}{\partial y^{2}} \\
u \frac{\partial C}{\partial x}+v \frac{\partial C}{\partial y}=D \frac{\partial^{2} C}{\partial y^{2}}
\end{gathered}
$$

with the boundary conditions,

$$
\begin{gathered}
v=v_{w}, \quad T=T_{s}(x), \quad C=C_{s}(x), \quad \mu \frac{\partial u}{\partial y}=\sigma_{T} \frac{\partial T}{\partial x}+\sigma_{C} \frac{\partial C}{\partial x} \quad \text { on } y=0 \\
u \longrightarrow u_{e}(x), \quad T \longrightarrow T_{m} \quad C \longrightarrow C_{m} \quad \text { as } y \longrightarrow \infty
\end{gathered}
$$

where $u$ and $v$ are the velocity components along $x$ and $y$ axes, $T$ is the fluid temperature, $C$ is the solutal concentration, $u_{e}(x)$ is the external velocity, $\alpha$ is the thermal diffusivity, $v$ is the kinematic viscosity, $D$ is the mass diffusivity, and $v_{w}$ is the constant suction $\left(v_{w}>0\right)$ or injection $\left(v_{w}<0\right)$ velocity, $\mu$ is the dynamic viscosity, and $\sigma_{T}$ and $\sigma_{C}$ are the rates of change of surface tension with temperature and solute concentration, respectively. As mentioned by Pop et al. [21], the forth condition of (2.2) represents the Marangoni coupling conditions at the interface (balance of the surface tangential momentum), having considered for the surface tension the linear relation given by

$$
\sigma=\sigma_{m}-\sigma_{T}\left(T-T_{m}\right)-\sigma_{C}\left(C-C_{m}\right), \quad \sigma_{T}=-\frac{\partial \sigma}{\partial T}, \sigma_{C}=-\frac{\partial \sigma}{\partial C} .
$$

Following Pop et al. [21], we define the following nondimensional variables:

$$
\begin{gathered}
x=L_{0}+X L, \quad y=\delta L Y, \quad u=U_{c} U, \quad v=\delta U_{c} V, \\
T=T_{m}+t \Delta T, \quad C=C_{m}+\phi \Delta C, \quad u_{e}(x)=U_{c} U_{e}(x), \quad v_{w}=U_{\mathrm{c}} L \delta^{2} V_{w},
\end{gathered}
$$

where $L_{0}$ locates the origin of the curvilinear abscissa $x, L$ is the extension of the relevant interface $S$, and $\Delta T$ and $\Delta C$ are positive increments of temperature and solute concentration linked to the temperature and solute concentration gradients imposed on the interface, 
respectively. Further, $\delta$ is a scale factor in the direction normal to the interface, and $U_{\mathrm{c}}$ is the reference velocity which is defined as $\delta=\operatorname{Re}^{-1 / 3}$ and $U_{c}=v /\left(L \delta^{2}\right)$ with $\operatorname{Re}=$ $\sigma_{T} \Delta T L / v \mu$ being the Reynolds number. Substituting (2.5) into (2.1), we obtain the following nondimensional equations:

$$
\begin{gathered}
\frac{\partial U}{\partial X}+\frac{\partial V}{\partial Y}=0 \\
U \frac{\partial U}{\partial X}+V \frac{\partial U}{\partial Y}=U_{e} \frac{d U_{e}}{d X}+\frac{\partial^{2} U}{\partial Y^{2}} \\
U \frac{\partial t}{\partial X}+V \frac{\partial t}{\partial Y}=\frac{1}{P_{r}} \frac{\partial^{2} t}{\partial Y^{2}} \\
U \frac{\partial \phi}{\partial X}+V \frac{\partial \phi}{\partial Y}=\frac{1}{\mathrm{Sc}} \frac{\partial^{2} \phi}{\partial Y^{2}}
\end{gathered}
$$

and the boundary conditions (2.2) and (2.3) reduce to

$$
\begin{gathered}
V=V_{w}, \quad t=t_{S}(X), \quad \phi=\phi_{s}(X), \quad \frac{\partial U}{\partial Y}=\frac{\partial t}{\partial X}+\varepsilon \frac{\partial \phi}{\partial X} \quad \text { on } Y=0, \\
U \longrightarrow U_{e}(X), \quad t \longrightarrow 0, \quad \phi \longrightarrow 0 \quad \text { as } Y \longrightarrow \infty
\end{gathered}
$$

where Pr is the Prandtl number, Sc is the Schmidt number, and $\varepsilon$ is the Marangoni parameter and is defined as

$$
\varepsilon=\frac{M a_{C}}{M a_{T}}=\frac{\sigma_{C} \Delta C}{\sigma_{T} \Delta T}
$$

with $M a_{C}=\sigma_{C} \Delta C L / \mu \alpha$ and $M a_{T}=\sigma_{T} \Delta T L / \mu \alpha$ being the solutal Marangoni number and thermal Marangoni number, respectively. It is also noted that positive $V_{w}$ is for fluid suction and negative for fluid injection at the wall. Equations (2.6) can be transformed into the corresponding ordinary differential equations by the following transformations (see Pop et al. [21]):

$$
\begin{gathered}
U=u_{0} X^{(2 \beta-1) / 3} f^{\prime}(\eta), \quad V=\frac{1}{3} u_{0} l_{0} x^{(\beta-2) / 3}\left((2-\beta) \eta f^{\prime}(\eta)-(1+\beta) f(\eta)\right), \\
t=-t_{0} X^{\beta} \theta(\eta), \quad \phi=-c_{0} X^{\beta} h(\eta), \quad U_{e}=u_{0} X^{(2 \beta-1) / 3}, \quad \eta=\frac{Y}{l_{0} x^{(2-\beta) / 3}},
\end{gathered}
$$

where $f^{\prime}(\eta), \theta(\eta)$, and $h(\eta)$ represent the velocity, temperature, and concentration profiles in the similarity plane and $\eta$ being the similarity variable. The constant scale factors $u_{0}, t_{0}, c_{0}$, and $l_{0}$ are chosen in order to simplify the equations, and these must satisfy the following conditions:

$$
u_{0} l_{0}^{2}=\frac{3}{\beta+1}, \quad \frac{t_{0} l_{0}}{u_{0}}=\frac{1}{\beta}, \quad \frac{c_{0}}{t_{0}}=1
$$


If we take $t_{0}=1$ or $c_{0}=1$ (due to arbitrariness of the temperature difference $\Delta T$ or the solutal concentration difference $\Delta C$ ), then $l_{0}$ and $u_{0}$ are uniquely determined as

$$
l_{0}=\left(\frac{3}{1+\beta}\right)^{1 / 3} \beta^{-1 / 3}, \quad u_{0}=\left(\frac{3}{1+\beta}\right)^{1 / 3} \beta^{2 / 3}
$$

The transformed ordinary differential equations are

$$
\begin{gathered}
f^{\prime \prime \prime}+f f^{\prime \prime}+\frac{2 \beta-1}{\beta+1}\left(1-f^{\prime 2}\right)=0, \\
\frac{1}{\operatorname{Pr}} \theta^{\prime \prime}+f \theta^{\prime}-\frac{3 \beta}{1+\beta} f^{\prime} \theta=0, \\
\frac{1}{\mathrm{Sc}} h^{\prime \prime}+f h^{\prime}-\frac{3 \beta}{1+\beta} f^{\prime} h=0
\end{gathered}
$$

along with the boundary conditions

$$
\begin{gathered}
f(0)=f_{0}, \quad f^{\prime \prime}(0)=-1-\varepsilon, \quad \theta(0)=1, \quad h(0)=1, \\
f^{\prime}(\infty)=1, \quad \theta(\infty)=0, \quad h(\infty)=0,
\end{gathered}
$$

where $f_{0}(>0)$ is the constant suction parameter and $f_{0}(<0)$ is the constant injection parameter.

\section{Results and Discussion}

The system of transformed governing equations (2.12) along with the boundary equations (2.13) is solved numerically using the shooting method. Tables 1, 2, and 3 illustrate the influence of the suction and injection parameter $f_{0}=1,0$, and -1 on the surface velocity, $f^{\prime}(0)$, surface temperature, $-\theta^{\prime}(0)$, and surface concentration, $-h^{\prime}(0)$ for different values of the similarity parameter, $\beta$ and different values of the Schmidt number, Sc in the case of Marangoni parameter, $\varepsilon=0,1$, and -1 . Further, the Prandtl number, $\mathrm{Pr}$, is taken to be $\operatorname{Pr}=0.7$ corresponding to air and the Schmidt number; Sc has the following values: $\mathrm{Sc}=0.22$ (hydrogen), 0.6 (water), 0.75 (oxygen), and 0.78 (ammonia). It should be noticed that the results given in the parentheses ( ) are the second (dual) solutions. Results obtained by Pop et al. [21] for the case of impermeable surface are also included in these tables. It is clearly seen that the results agree well in all the three tables.

Figures 1, 2, and 3 present the variations of the surface velocity, temperature, and concentration with $\beta$, respectively, when $\operatorname{Pr}=0.7, \mathrm{Sc}=0.78$ in the case of $\varepsilon=0$ (Marangoni effect neglected) with the effect of the parameter $f_{0}$. The dashed line refers to the second solution of the problem. From these figures, we can see that the second solutions exist for $\beta<0.5$. This discovery is consistent with the statement given in Pop et al. [21], that for $\beta<0.5$, the solutions are not unique. Not only that it can be observed from the figures but the effects of suction or injection parameter can be clearly seen when $\beta>0.4$. The imposition of suction $\left(f_{0}>0\right)$ at the surface has the tendency to reduce the velocity but increase the temperature and concentration gradients along the interface. Meanwhile, the opposite results are observed 


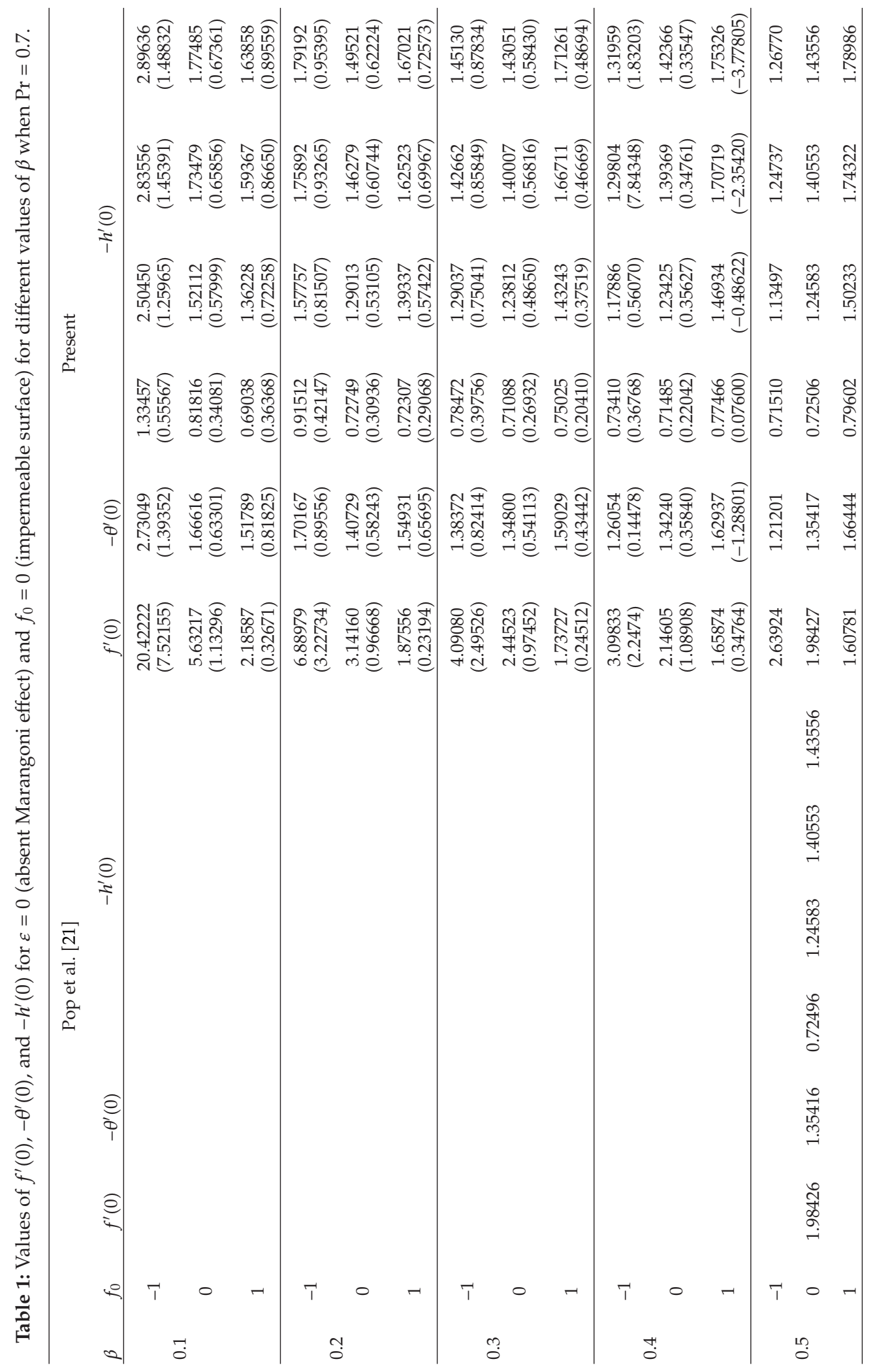


Mathematical Problems in Engineering

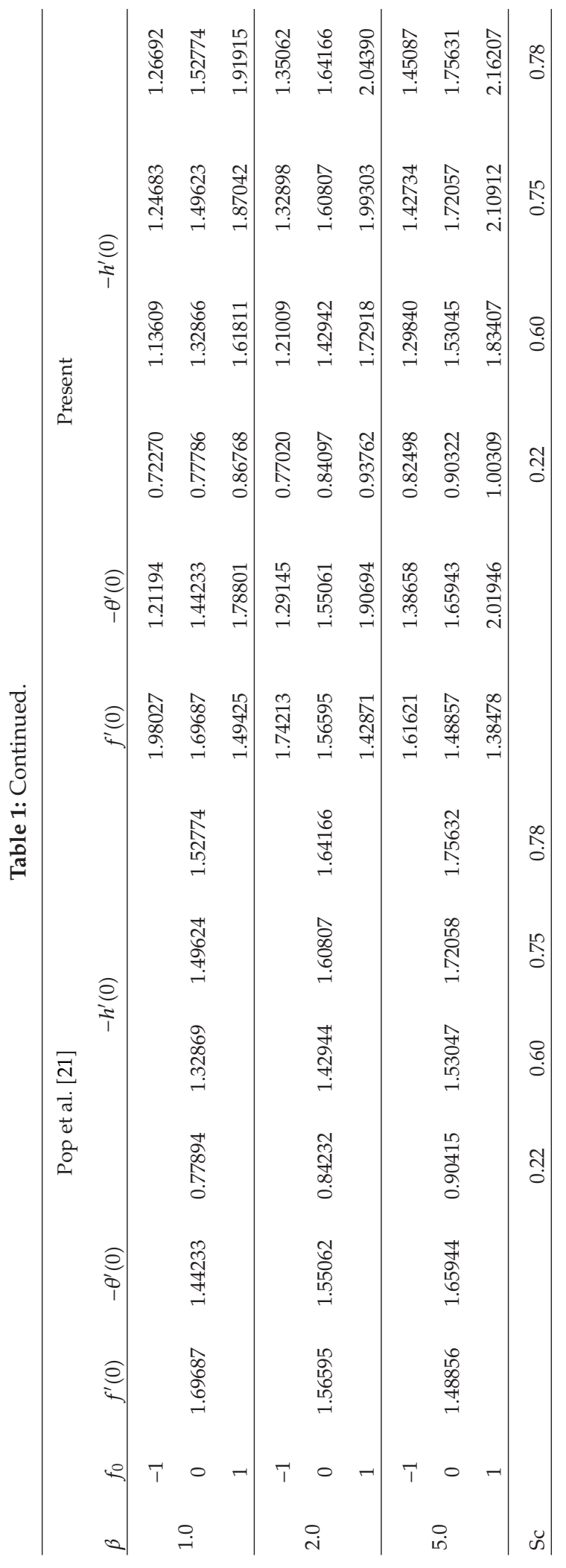




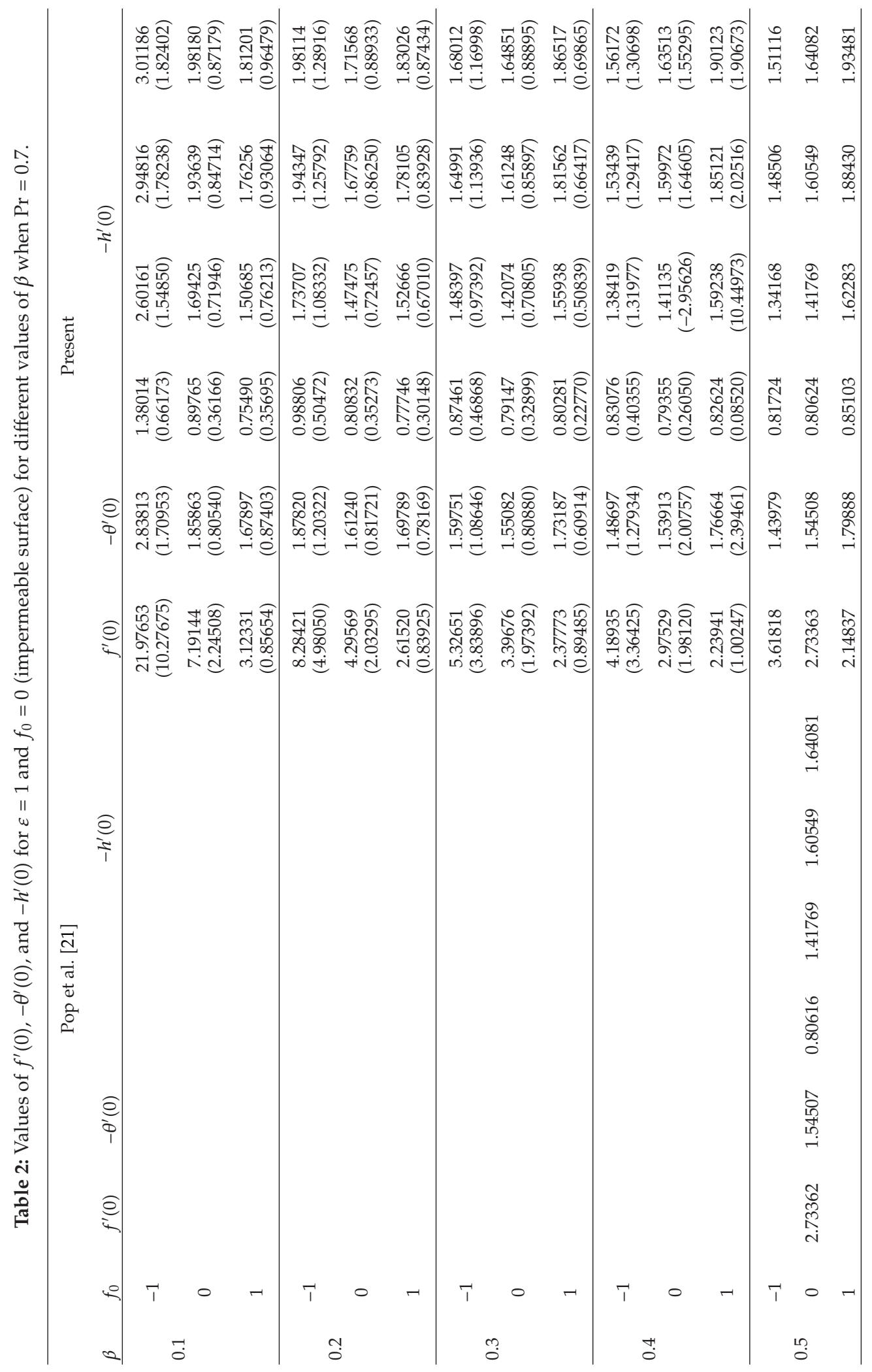




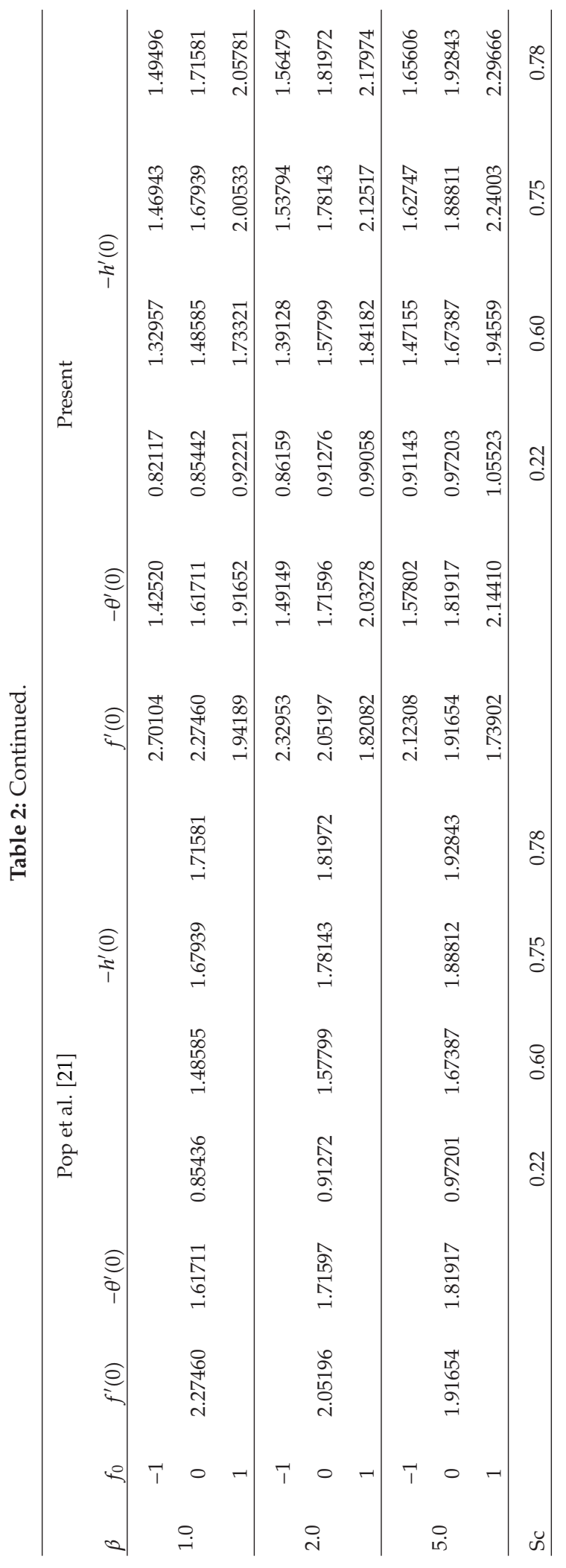




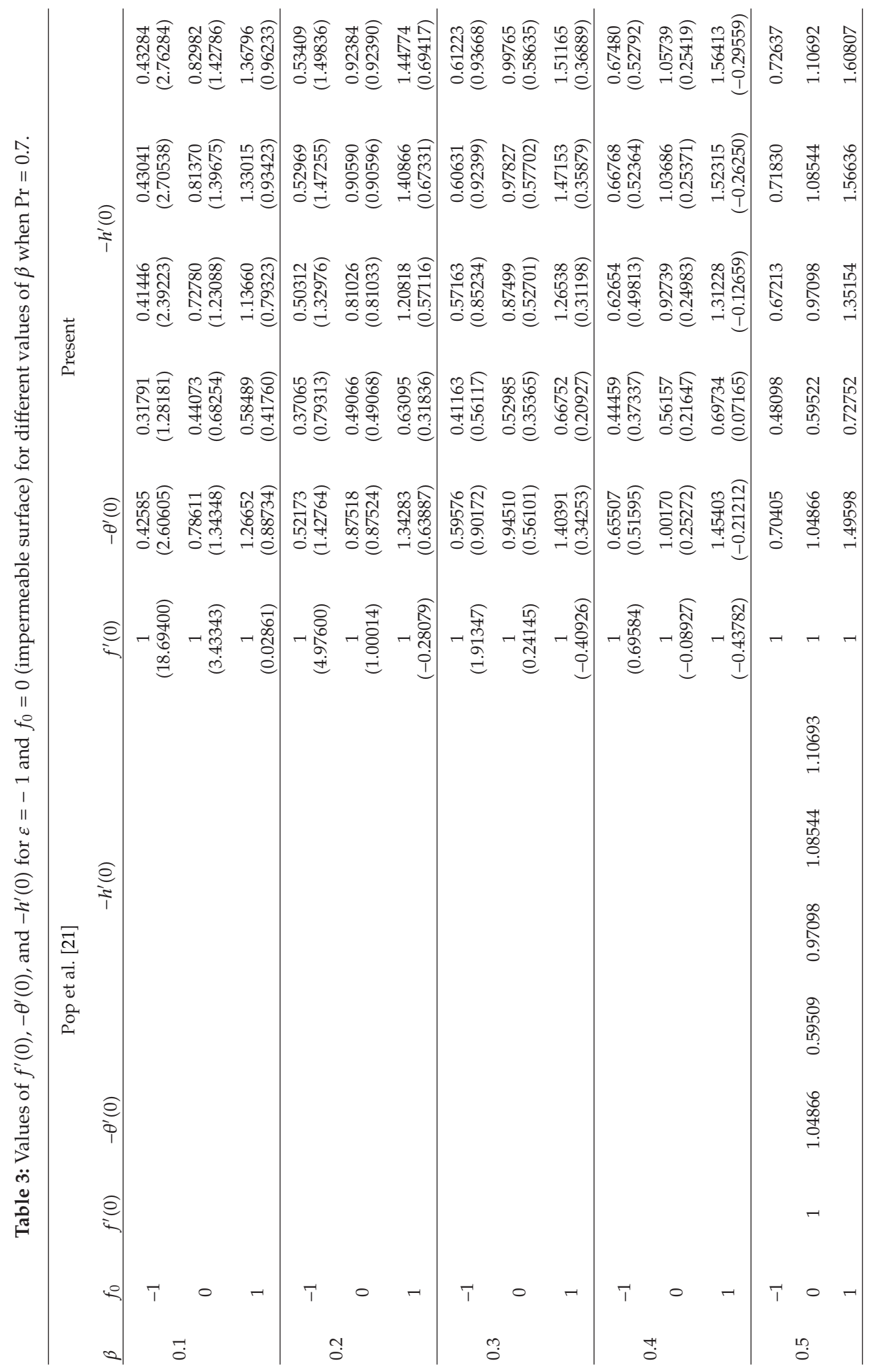




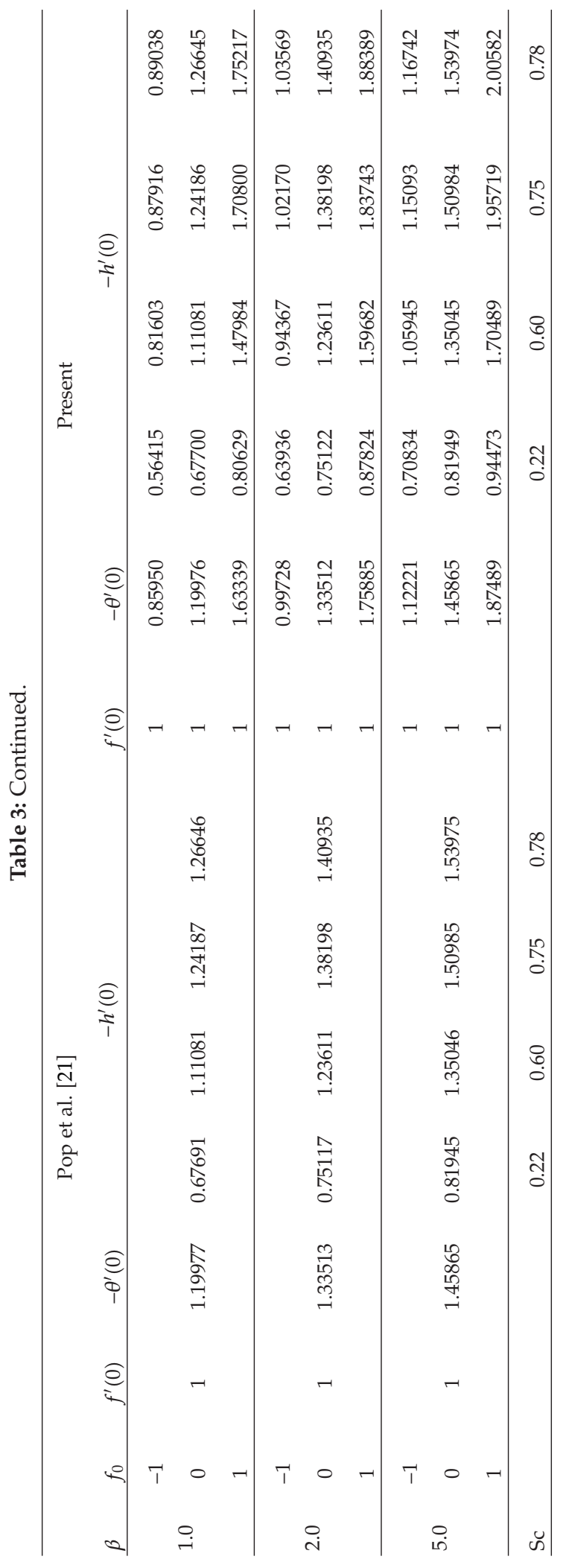




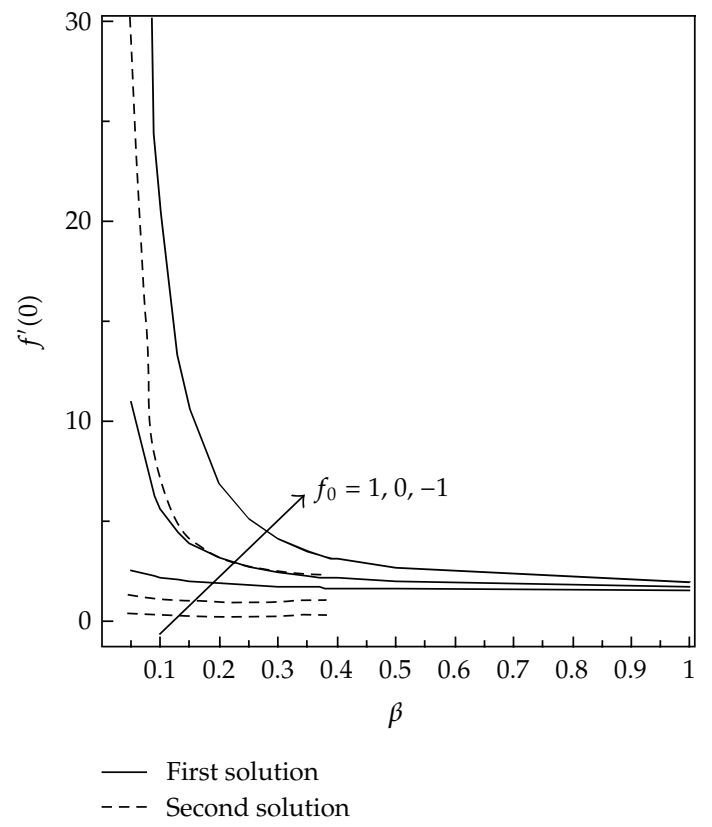

Figure 1: Variation of the surface velocity with $\beta$ when $\operatorname{Pr}=0.7, \mathrm{Sc}=0.78$, and $\varepsilon=0$.

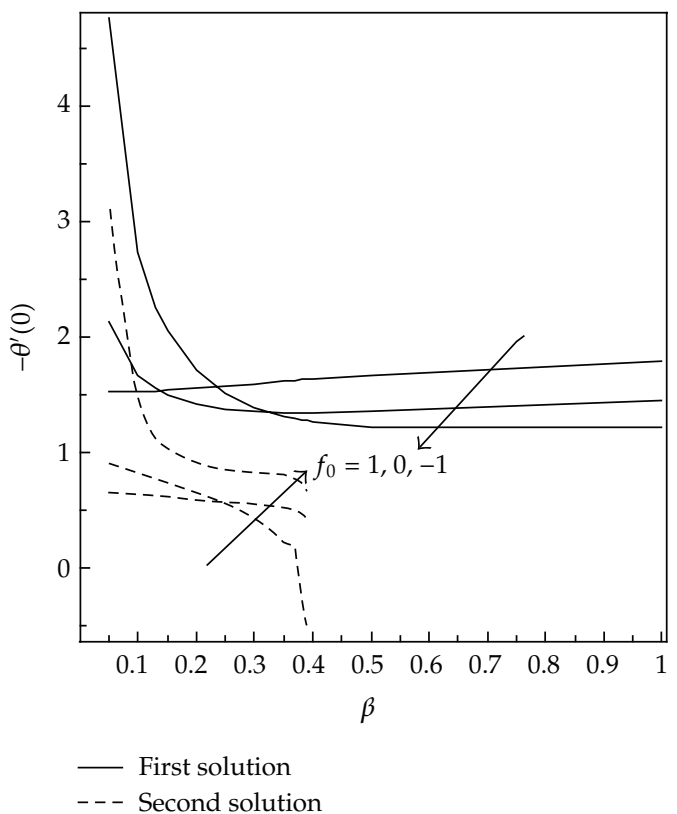

Figure 2: Variation of the surface temperature with $\beta$ when $\operatorname{Pr}=0.7, \mathrm{Sc}=0.78$, and $\varepsilon=0$.

for the case of surface injection $\left(f_{0}<0\right)$, an increase in the surface velocity and decrease in the surface temperature and concentration gradients. Hence, consequently, the interface heat transfer and the interface mass transfer will decrease as well. 


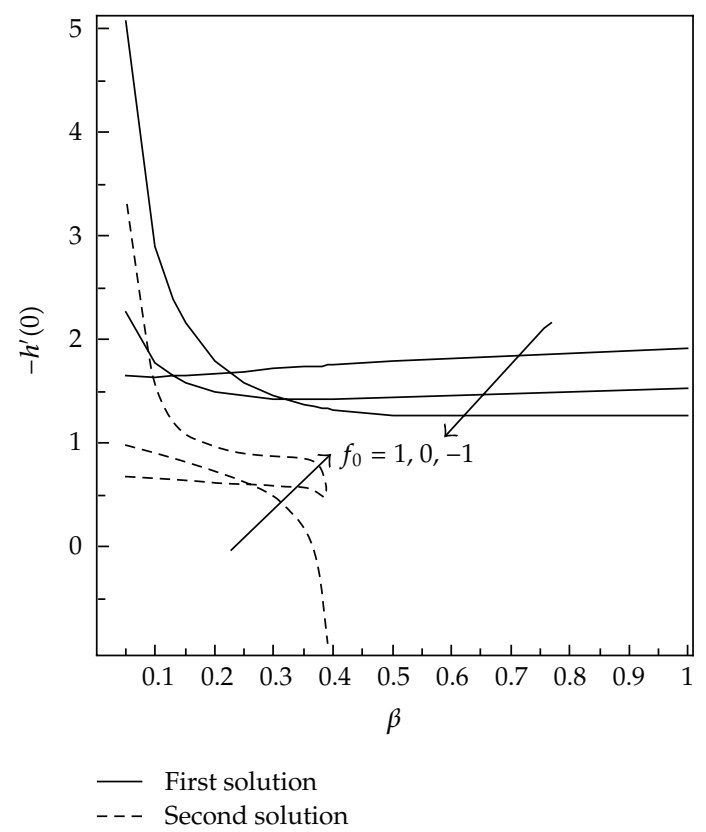

Figure 3: Variation of the surface concentration with $\beta$ when $\operatorname{Pr}=0.7, \mathrm{Sc}=0.78$, and $\varepsilon=0$.

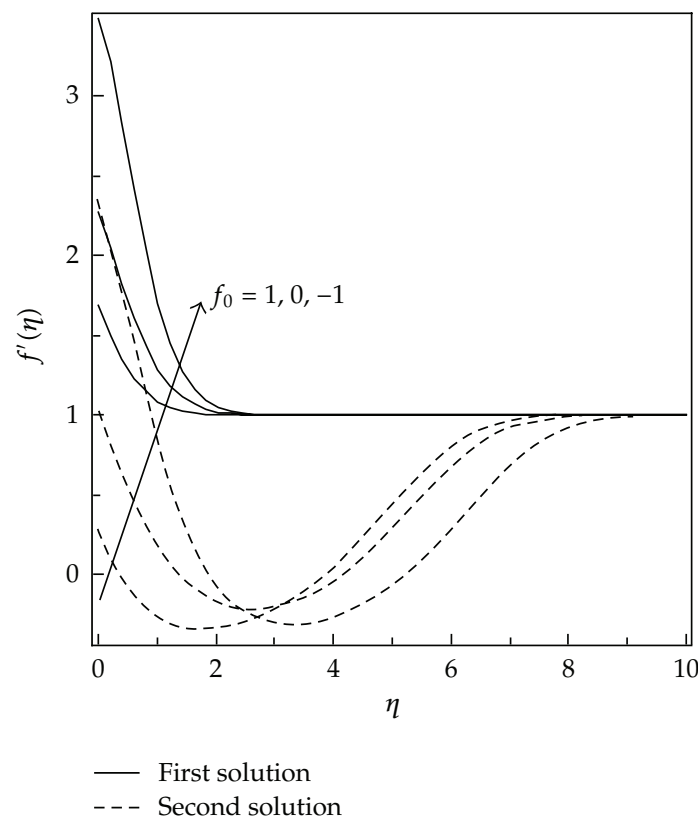

Figure 4: Effects of $f_{0}$ on the velocity profiles when $\operatorname{Pr}=0.7, \mathrm{Sc}=0.78, \beta=0.35$, and $\varepsilon=0$.

Figures 4 to 12 illustrate the effects of parameter $f_{0}$ on the velocity $f^{\prime}(\eta)$, temperature $\theta(\eta)$, and concentration $h(\eta)$ profiles when $\operatorname{Pr}=0.7$ (air), Sc $=0.78$ (ammonia), and $\beta=0.35$ in the case of $\varepsilon=0,1$, and -1 . The influence of $f_{0}$ on the velocity profiles is depicted in Figures 4 , 5 , and 6 . The figures show that the suction parameter decreases the velocity profiles, and the 


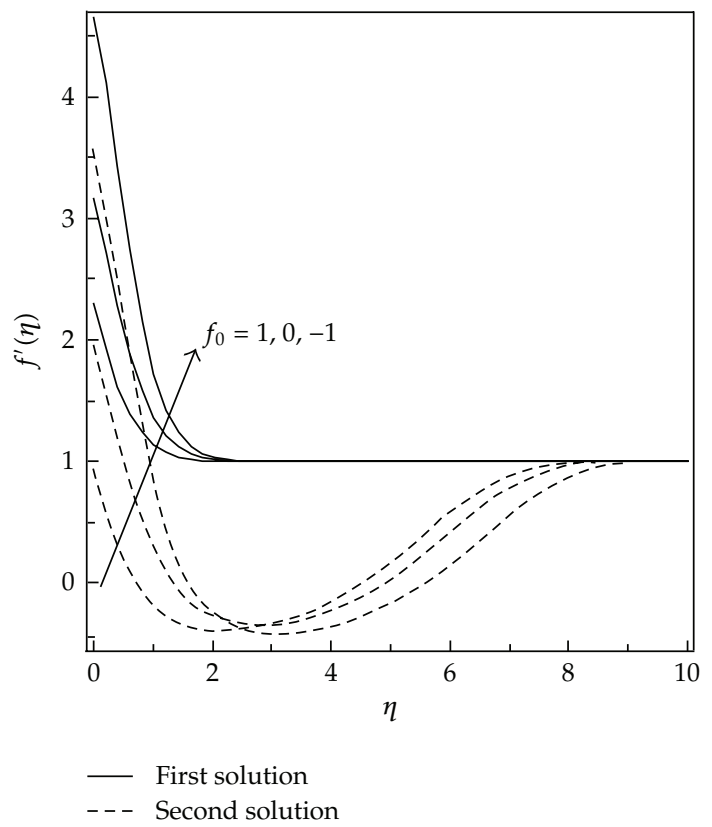

Figure 5: Effects of $f_{0}$ on the velocity profiles when $\operatorname{Pr}=0.7, \mathrm{Sc}=0.78, \beta=0.35$, and $\varepsilon=1$.

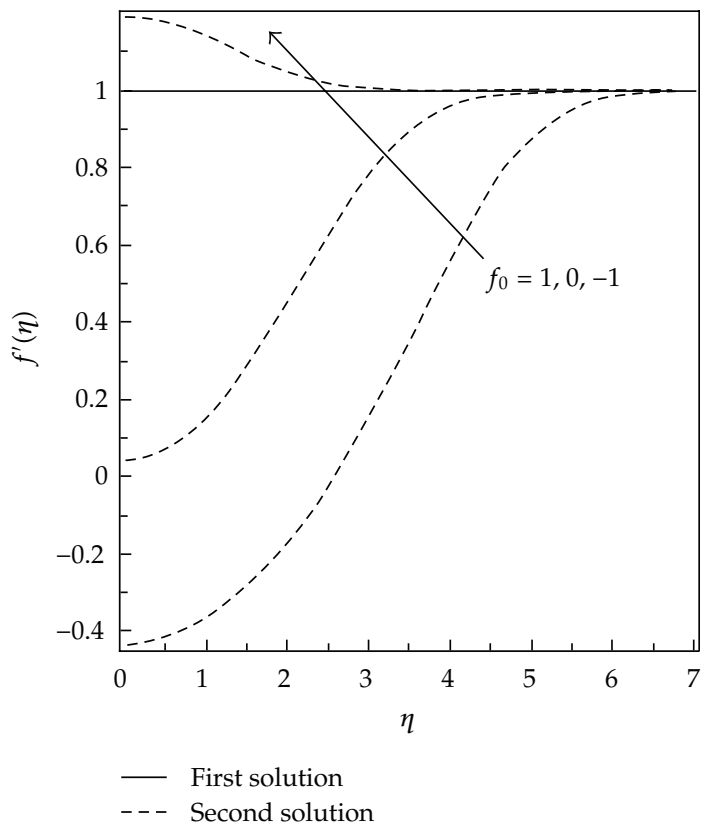

Figure 6: Effects of $f_{0}$ on the velocity profiles when $\operatorname{Pr}=0.7, \mathrm{Sc}=0.78, \beta=0.35$, and $\varepsilon=-1$.

injection parameter increases the velocity profiles for the case of the Marangoni parameter $\varepsilon=$ 0 and 1. Further, in Figures 7, 8, and 9, we can see the effects of $f_{0}$ on the temperature profiles. The figures indicate that for $\varepsilon=0,1$, and -1 , imposition of the suction parameter tends to 


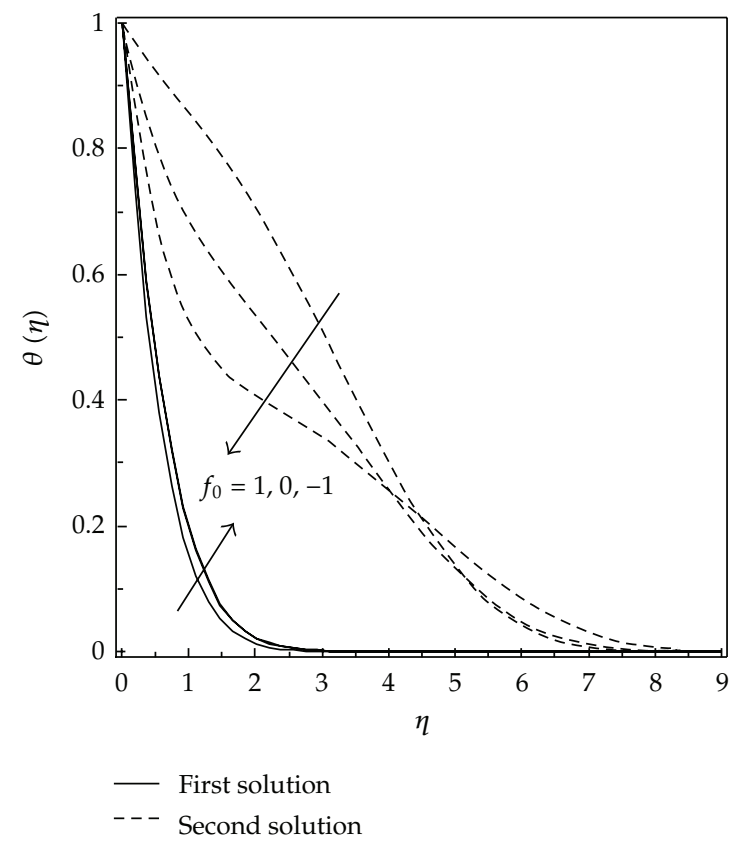

Figure 7: Effects of $f_{0}$ on the temperature profiles when $\operatorname{Pr}=0.7, \mathrm{Sc}=0.78, \beta=0.35$, and $\varepsilon=0$.

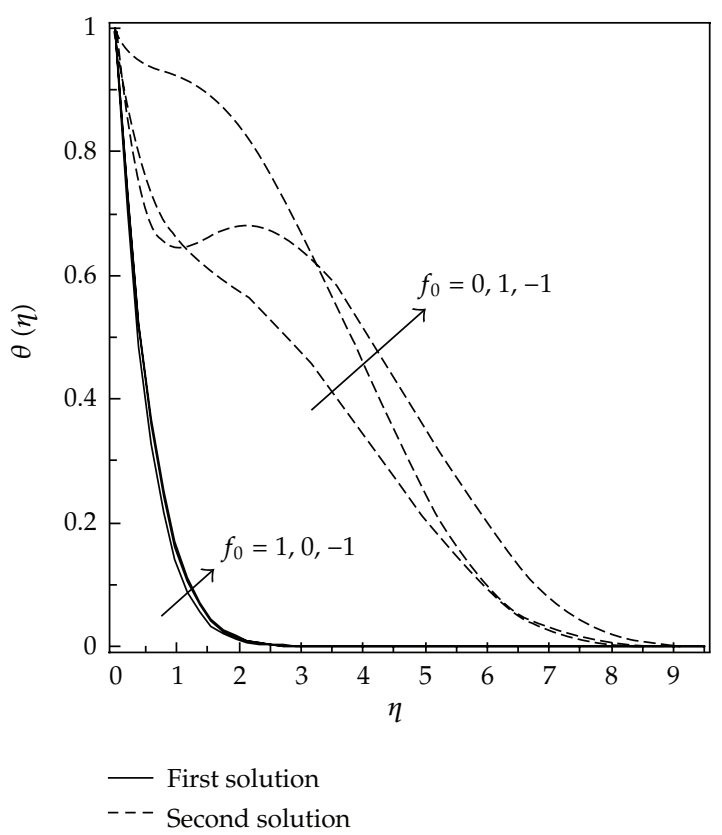

Figure 8: Effects of $f_{0}$ on the temperature profiles when $\operatorname{Pr}=0.7, \mathrm{Sc}=0.78, \beta=0.35$, and $\varepsilon=1$.

reduce the temperature profiles, whereas the injection parameter increases the profiles. It should be noticed that the second solutions in these cases have positive values. Besides, it can also be seen that reduction in Marangoni parameter $\varepsilon$ causes the dual solutions to be 


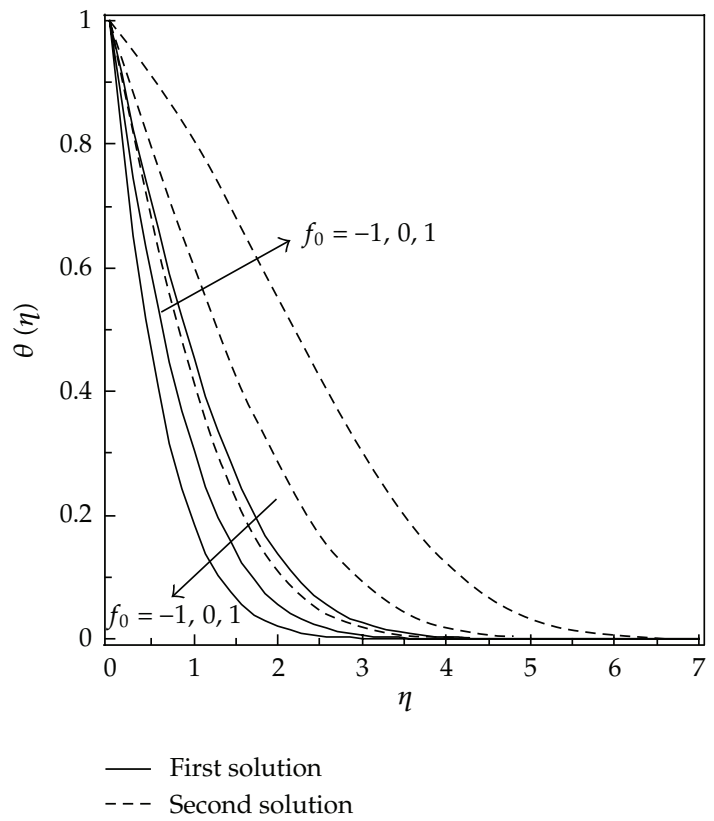

Figure 9: Effects of $f_{0}$ on the temperature profiles when $\operatorname{Pr}=0.7, \mathrm{Sc}=0.78, \beta=0.35$, and $\varepsilon=-1$.

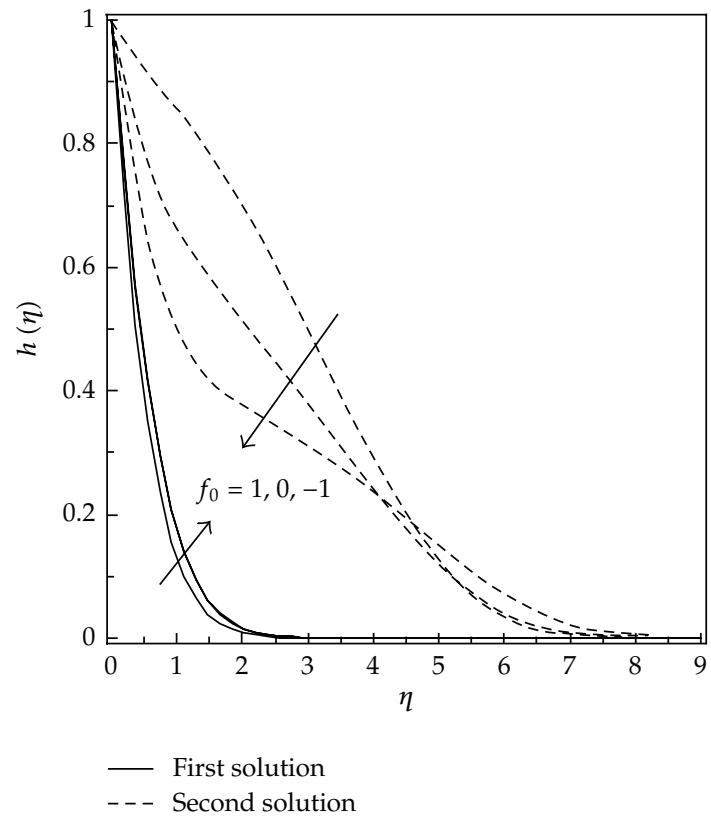

Figure 10: Effects of $f_{0}$ on the concentration profiles when $\operatorname{Pr}=0.7, \mathrm{Sc}=0.78, \beta=0.35$, and $\varepsilon=0$.

more stable. On the other hand, the effects of suction or injection parameter on concentration profiles $h(\eta)$ are shown in Figures 10, 11, and 12 and are similar to the concentration profiles. 


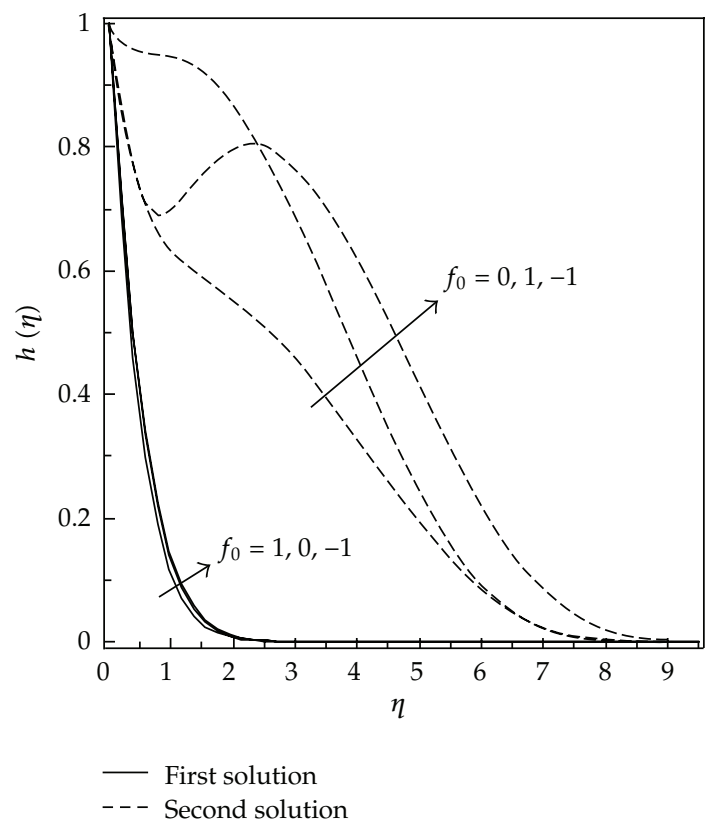

Figure 11: Effects of $f_{0}$ on the concentration profiles when $\operatorname{Pr}=0.7, \mathrm{Sc}=0.78, \beta=0.35$, and $\varepsilon=1$.

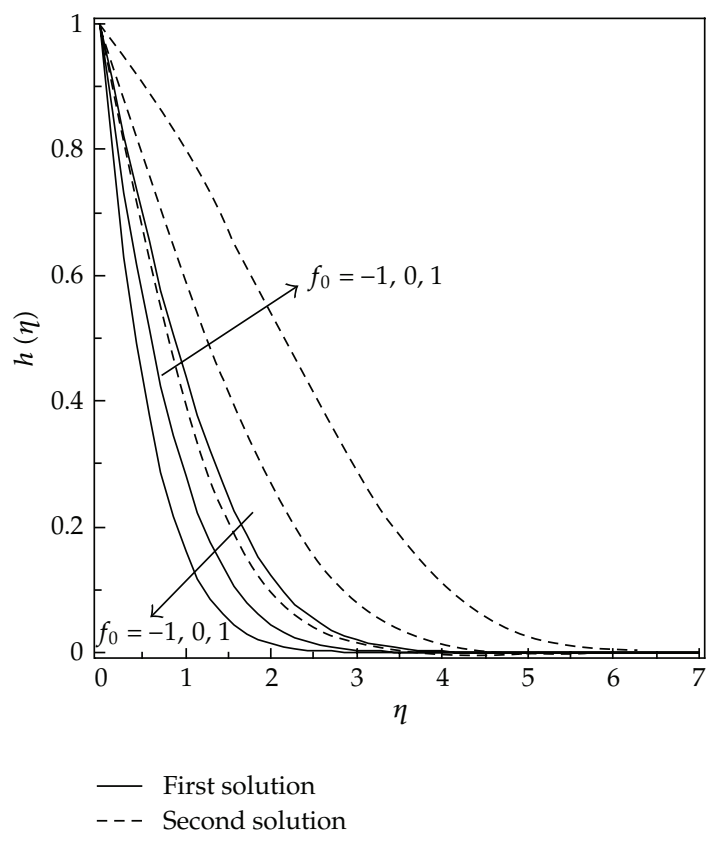

Figure 12: Effects of $f_{0}$ on the concentration profiles when $\operatorname{Pr}=0.7, \mathrm{Sc}=0.78, \beta=0.35$, and $\varepsilon=-1$.

\section{Conclusions}

The present work deals with the thermosolutal Marangoni forced convection boundary layer flow as considered by Pop et al. [21]. We extended the paper by taking into consideration 
the effects of suction or injection. On the other hand, we also studied the existence of dual similarity solutions in the present problem. Further, the governing equations are transformed into ordinary differential equations and are then solved numerically using the shooting method. The effects of suction or injection parameter on the flow and heat transfer characteristics are studied. In general, imposition of suction is to decrease the velocity, temperature, and concentration profiles, whereas injection shows the opposite effects. On the other hand, the second (dual) solutions are discovered to exist when similarity parameter $\beta<0.5$.

\section{Acknowledgment}

The authors gratefully acknowledged the financial support received in the form of an FRGS research grant from the Ministry of Higher Education, Malaysia.

\section{References}

[1] T. Kuroda, “The Marangoni effect and its artistic application," Forma, vol. 15, pp. 203-204, 2000.

[2] K. Arafune and A. Hirata, "Interactive solutal and thermal marangoni convection in a rectangular open boat," Numerical Heat Transfer Part A, vol. 34, no. 4, pp. 421-429, 1998.

[3] D. M. Christopher and B. Wang, "Prandtl number effects for Marangoni convection over a flat surface," International Journal of Thermal Sciences, vol. 40, no. 6, pp. 564-570, 2001.

[4] A. J. Chamkha, I. Pop, and H. S. Takhar, "Marangoni mixed convection boundary layer flow," Meccanica, vol. 41, no. 2, pp. 219-232, 2006.

[5] C. Golia and A. Viviani, "Non isobaric boundary layers related to Marangoni flows," Meccanica, vol. 21, no. 4, pp. 200-204, 1986.

[6] R. F. Dressler and N. S. Sivakumaran, "Non-contaminating method to reduce Marangoni convection in microgravity float zones," Journal of Crystal Growth, vol. 88, no. 1, pp. 148-158, 1988.

[7] A. Al-Mudhaf and A. J. Chamkha, "Similarity solutions for MHD thermosolutal Marangoni convection over a flat surface in the presence of heat generation or absorption effects," Heat and Mass Transfer, vol. 42, no. 2, pp. 112-121, 2005.

[8] E. Magyari and A. J. Chamkha, "Exact analytical results for the thermosolutal MHD Marangoni boundary layers," International Journal of Thermal Sciences, vol. 47, no. 7, pp. 848-857, 2008.

[9] N. M. Arifin, R. Nazar, and I. Pop, “Non-isobaric marangoni boundary layer flow for $\mathrm{Cu} \mathrm{Al}_{2} \mathrm{O}_{3}$ and $\mathrm{TiO}_{2}$ nanoparticles in a water based fluid," Meccanica. In press.

[10] I. Pop and T. Watanabe, "The effects of uniform suction or injection on the boundary layer flow and heat transfer on a continuous moving surface," Technische Mechanik, vol. 13, pp. 49-54, 1992.

[11] E. A. Hamza, "Suction and injection effects on a similar flow between parallel plates," Journal of Physics D, vol. 32, no. 6, pp. 656-663, 1999.

[12] M. H. Shojaefard, A. R. Noorpoor, A. Avanesians, and M. Ghaffarpour, "Numerical investigation of flow control by suction and injection on a subsonic airfoil," American Journal of Applied Sciences, vol. 2, no. 10, pp. 1474-1480, 2005.

[13] F. R. de Hoog, B. Laminger, and R. Weiss, "A numerical study of similarity solutions for combined forced and free convection," Acta Mechanica, vol. 51, no. 3-4, pp. 139-149, 1984.

[14] D. B. Ingham, "Singular and non-unique solutions of the boundary-layer equations for the flow due to free convection near a continuously moving vertical plate," Zeitschrift für angewandte Mathematik und Physik, vol. 37, no. 4, pp. 559-572, 1986.

[15] N. Ramachandran, T. S. Chen, and B. F. Armaly, "Mixed convection in stagnation flows adjacent to vertical surfaces," Journal of Heat Transfer, vol. 110, no. 2, pp. 373-377, 1988.

[16] H. Xu and S.-J. Liao, "Dual solutions of boundary layer flow over an upstream moving plate," Communications in Nonlinear Science and Numerical Simulation, vol. 13, no. 2, pp. 350-358, 2008.

[17] A. Ishak, R. Nazar, N. M. Arifin, and I. Pop, "Dual solutions in magnetohydrodynamic mixed convection flow near a stagnation-point on a vertical surface," Journal of Heat Transfer, vol. 129, no. 9, pp. 1212-1216, 2007. 
[18] A. Ishak, R. Nazar, N. M. Arifin, and I. Pop, "Dual solutions in mixed convection flow near a stagnation point on a vertical porous plate," International Journal of Thermal Sciences, vol. 47, no. 4, pp. 417-422, 2008.

[19] A. Ishak, R. Nazar, and I. Pop, "Dual solutions of the extended Blasius problem," Matematika, vol. 25, no. 2, pp. 107-111, 2009.

[20] A. Ridha, "On the dual solutions associated with boundary-layer equations in a corner," Journal of Engineering Mathematics, vol. 26, no. 4, pp. 525-537, 1992.

[21] I. Pop, A. Postelnicu, and T. Groşan, "Thermosolutal Marangoni forced convection boundary layers," Meccanica, vol. 36, no. 5, pp. 555-571, 2001. 


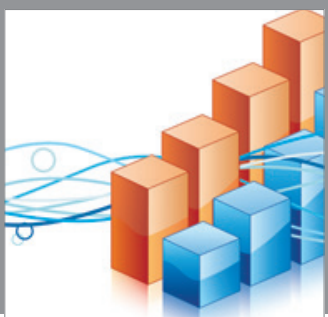

Advances in

Operations Research

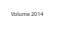

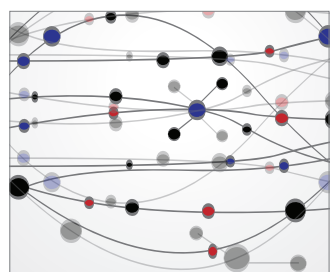

\section{The Scientific} World Journal
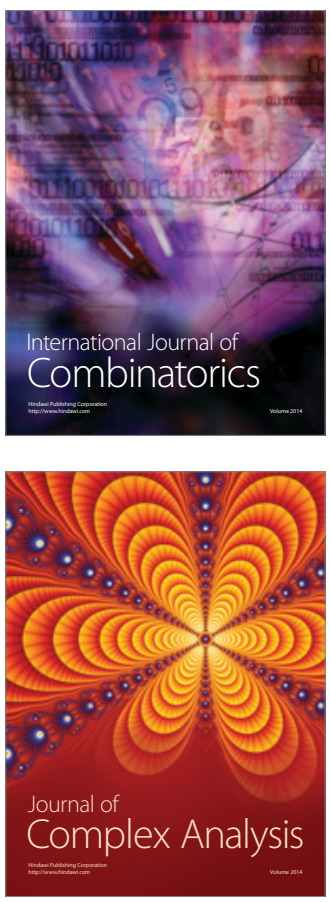

International Journal of

Mathematics and

Mathematical

Sciences
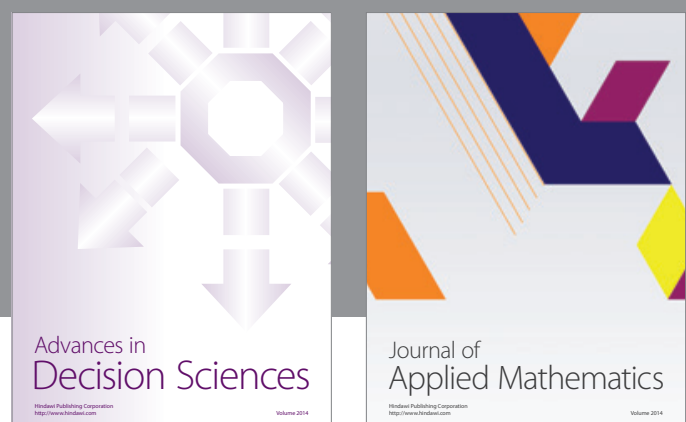

Journal of

Applied Mathematics
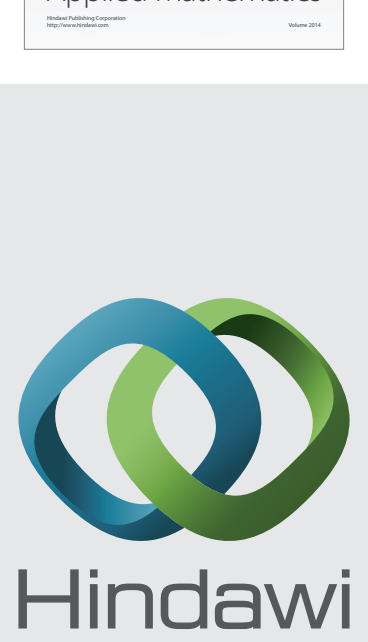

Submit your manuscripts at http://www.hindawi.com
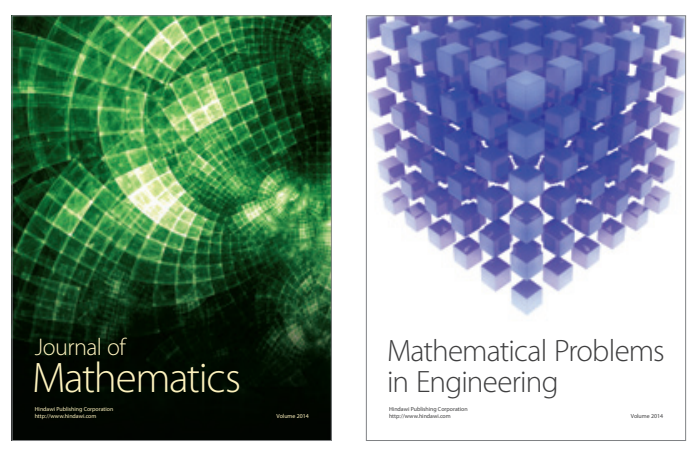

Mathematical Problems in Engineering
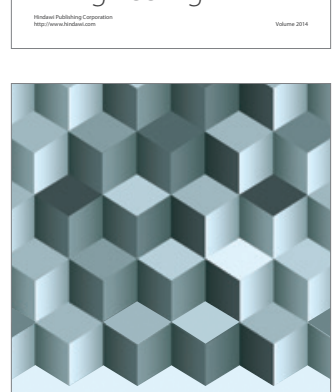

Journal of

Function Spaces
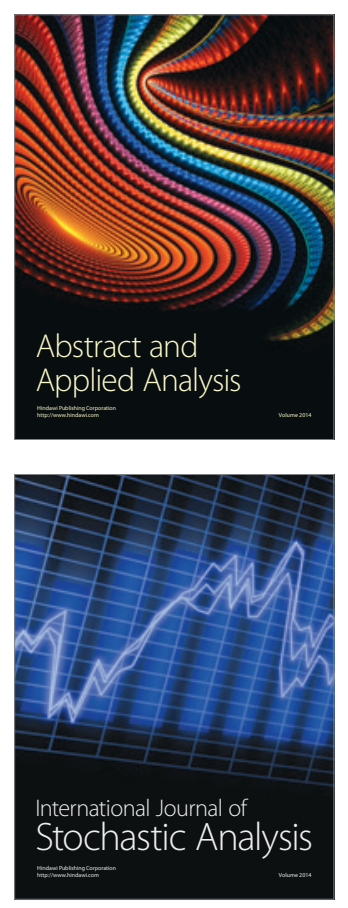

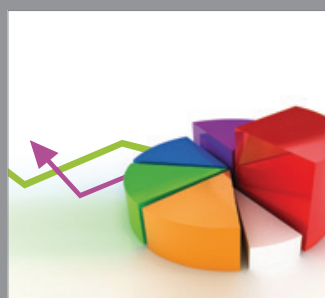

ournal of

Probability and Statistics

Promensencen
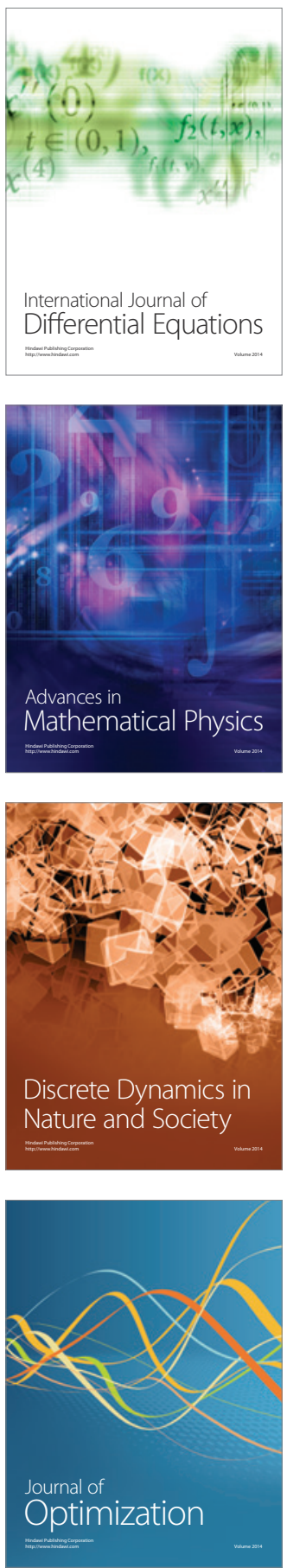